\title{
Evaluation of monsoon seasonality and the tropospheric biennial oscillation transitions in the CMIP models
}

\author{
Yue Li, ${ }_{1}^{1}$ Nicolas C. Jourdain, ${ }^{1}$ Andréa S. Taschetto, ${ }^{1}$ Caroline C. Ummenhofer, ${ }^{2}$ \\ Karumuri Ashok, ${ }^{3}$ and Alexander Sen Gupta ${ }^{1}$ \\ Received 31 July 2012; revised 17 September 2012; accepted 25 September 2012; published 26 October 2012.
}

[1] Characteristics of the Indian and Australian summer monsoon systems, their seasonality and interactions are examined in a variety of observational datasets and in the Coupled Model Intercomparison Project Phase 3 and 5 (CMIP3 and CMIP5) climate models. In particular, it is examined whether preferred monsoon transitions between the two regions and from one year to another, that form parts of the Tropospheric Biennial Oscillation, can lead to improved predictive skill. An overall improvement in simulation of seasonality for both monsoons is seen in CMIP5 over CMIP3, with most CMIP5 models correctly simulating very low rainfall rates outside of the monsoon season. The predictability resulting from each transition is quantified using a Monte Carlo technique. The transition from strong/weak Indian monsoon to strong/weak Australian monsoon shows $\sim 15 \%$ enhanced predictability in the observations, in estimating whether the following monsoon will be stronger/weaker than the climatology. Most models also successfully simulate this transition. However, enhanced predictability for other transitions is less clear. Citation: Li, Y., N. C. Jourdain, A. S. Taschetto, C. C. Ummenhofer, K. Ashok, and A. Sen Gupta (2012), Evaluation of monsoon seasonality and the tropospheric biennial oscillation transitions in the CMIP models, Geophys. Res. Lett., 39, L20713, doi:10.1029/ 2012 GL053322.

\section{Introduction}

[2] The Indian - Australian monsoon system affects approximately one-fourth of the world's population. As such, a thorough understanding of the monsoon variability is of vital importance for the population living in those areas. Both Indian and Australian monsoons undergo large year-to-year variations. Previous studies have suggested that this variability can be partly understood in terms of a quasi-biennial oscillation, whereby a relatively strong Indian monsoon is followed by a strong Australian monsoon half a year later and relatively weak Indian monsoon in the subsequent year (and vice versa) [Meehl, 1987]. This monsoonal see-saw is often referred to as Tropospheric Biennial Oscillation (TBO)

\footnotetext{
${ }^{1}$ Climate Change Research Centre, University of New South Wales, Sydney, New South Wales, Australia.

${ }^{2}$ Department of Physical Oceanography, Woods Hole Oceanographic Institution, Woods Hole, Massachusetts, USA.

${ }^{3}$ Centre for Climate Change Research, Indian Institute of Tropical Meteorology, Pune, India.

Corresponding author: Y. Li, Climate Change Research Centre, University of New South Wales, Sydney, NSW 2052, Australia. (yue.li@student.unsw.edu.au)

C2012. American Geophysical Union. All Rights Reserved. 0094-8276/12/2012GL053322
}

[Meehl, 1997]. Large-scale atmospheric circulation change and ocean-land temperature gradient are key ingredients of the TBO, with modulation by remote modes of variability, such as the El Niño-Southern Oscillation (ENSO) [Meehl and Arblaster, 2002].

[3] Previous studies have examined the possible mechanisms for the TBO and the individual transitions that make up the TBO. Meehl [1987] and Meehl and Arblaster [2002], for example examine the Indian-Australian in-phase transition when a strong (weak) Indian monsoon is followed by a strong (weak) Australian monsoon. They show that a direct forcing by ENSO tends to reinforce the transition, as an El Niño (La Niña) tends to suppress (enhance) both monsoons. According to $W u$ [2008] however, this transition can also occur independently of any ENSO influence via interactions confined to the Indian Ocean and Maritime Continent. A number of complementary mechanisms have also been proposed for the out-of-phase transition, i.e., from a strong (weak) Australian monsoon to a weak (strong) Indian monsoon. When the phase of ENSO changes just after an Australian monsoon season, it can directly drive the out-ofphase transition [e.g., Meehl and Arblaster, 2002]. In another mechanism, cool Indian Ocean SST anomalies resulting from a combined strong Indian monsoon and La Niña conditions may persist through to the next year to produce a weak Indian monsoon [Meehl and Arblaster, 2002]. At the same time the persistence of La Niña drives a strong Australian monsoon. Thus we see a strong Australian monsoon followed by a weak Indian monsoon, although the strong Australian monsoon is not the cause of the Indian monsoon anomaly. Finally, $W u$ [2009] also proposes a mechanism that is independent of ENSO in which the Australian monsoon generates SST anomalies in the north Indian Ocean, which in turn influence the subsequent Indian monsoon. TBO-like variability has been successfully reproduced in both simple box models [e.g., Chang and Li, 2000] and coupled climate models [Nanjundiah et al., 2005]. Previous studies have shown considerable decadal variability in the presence of the TBO (e.g., K. Ashok et al., Decadal changes in the relationship between the Indian and Australian summer monsoons, submitted to Climate Dynamics, 2012).

[4] Using a Monte Carlo sampling of observed monsoon rainfall, Fasullo [2004] examined the Indian-Indian monsoon transition. He found that the success of this transition was highly dependent on the co-occurrence of ENSO events, suggesting that ENSO-related mechanisms are a necessary condition for the existence of a TBO. In this study we use a similar approach to Fasullo [2004] to examine all monsoon transitions in several observational products and in the CMIP3 and CMIP5 historical simulations. In particular, we quantify the enhanced predictive skill, resulting from each of the 

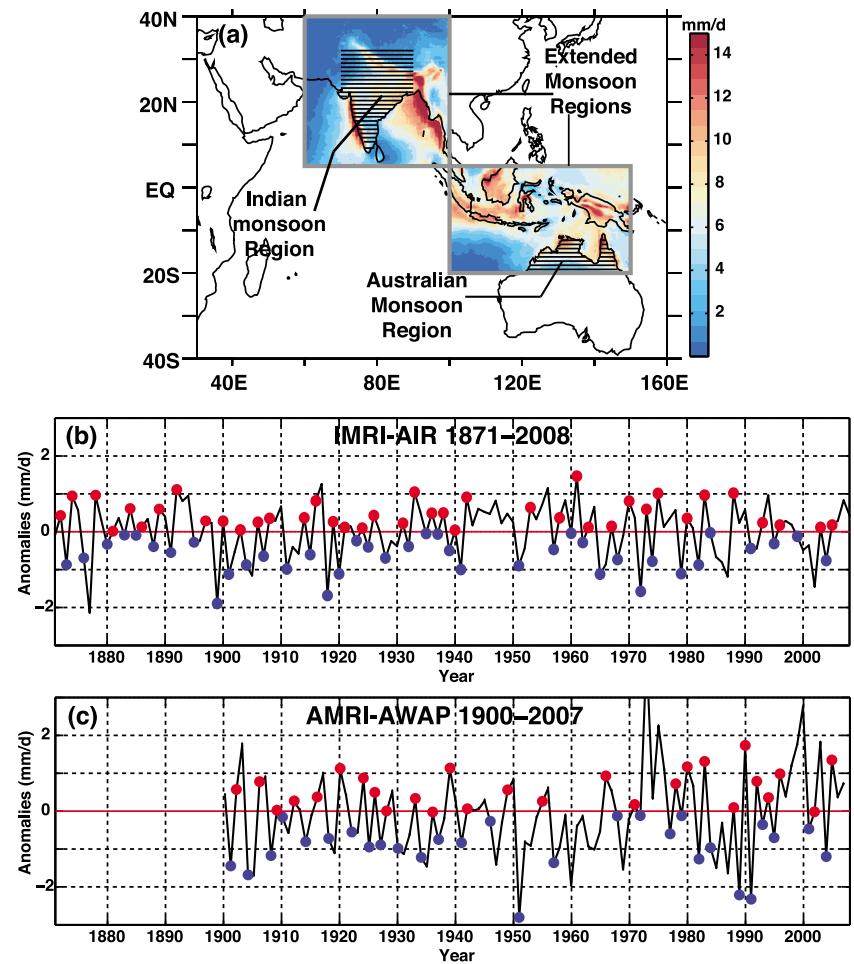

Figure 1. (a) The map showing the continental Indian and Australian monsoon regions (shaded) used to calculated the IMRI and AMRI, and the extended monsoon regions (boxes: $5^{\circ} \mathrm{N}-40^{\circ} \mathrm{N}, 60^{\circ} \mathrm{E}-100^{\circ} \mathrm{E}$ and $20^{\circ} \mathrm{S}-5^{\circ} \mathrm{N}, 100^{\circ} \mathrm{E}-150^{\circ} \mathrm{E}$ ), including the ocean based on Meehl and Arblaster [2002]. (b) The IMRI-AIR is the anomaly derived from average JJAS rainfall over the Indian subcontinent, and (c) the AMRI-AWAP is the anomaly averaged from DJFM rainfall over North Australia. Red/blue circles in Figures 1b and $1 \mathrm{c}$ represent the successful positive/negative transition years, respectively, relating to Indian-Indian and AustralianAustralian transitions.

transitions, i.e., the probability that the following monsoon rainfall will be stronger or weaker than the climatological average.

\section{Methodology}

[5] In order to examine Indian and Australian monsoon variability, we define the Indian Monsoon Rainfall Index (IMRI) and the Australian Monsoon Rainfall Index (AMRI). The reference IMRI is based on mean JJAS (June to September) All-Indian Monsoon Rainfall (AIR) computed by Parthasarathy et al. [1995] (1871-2008, referred to as IMRI-AIR, see Figure 1a). Other IMRIs are similarly defined using other observational datasets (see below) for the shaded area shown in Figure 1a. These indices differ from the IMRI-AIR in that the Himalaya is entirely included in our domain in order to be consistent with various coarse model grids. The Australian Monsoon Rainfall Index (AMRI) is defined as the mean DJFM (December to March) rainfall anomaly over northern Australia (Figure 1a). In this paper, the reference AMRI is derived from the high-quality daily rainfall data from the Australian Water Availability Project (AWAP) (1900-2007; resolution $0.1^{\circ} \times 0.1^{\circ}$ [Jones et al.,
2009]) (referred to as AMRI-AWAP). In order to test the sensitivity of our results to the choice of dataset, we also calculate the IMRI and AMRI from two global gridded precipitation datasets: the Climate Prediction Center Merged Analysis of Precipitation dataset (CMAP; resolution $2.5^{\circ} \times$ $2.5^{\circ}$; 1979-2008) [Xie and Arkin, 1996] and the Global Precipitation Climatology Centre dataset (GPCC; resolution $\left.1^{\circ} \times 1^{\circ} ; 1901-2010\right)$ [Rudolf et al., 2010]. The IMRI and AMRI are also calculated for 24 CMIP3 models simulations (20c3m experiment) covering approximately 1860-2000, and for 23 CMIP5 simulations (historical experiment) covering 1850-2005 (some models contain more than one member).

\section{Results}

\subsection{Seasonality}

[6] For all three observed Indian rainfall datasets, the four wettest months extend from June to September with maximum rainfall in July (Figure 2a). The CMIP models show a range of behaviors. Eleven out of 24 CMIP3 models (Figure 2a) and 11 out of 23 CMIP5 models (Figure 2c) correctly simulate peak rainfall in July, with several models with peak rainfall delayed by one month. Three CMIP3 models have large timing biases: the mpi echam5 and csiro mk3.5/ipsl$\mathrm{cm} 4$ peak two months early and late respectively. There is also considerable spread in the amplitude of the seasonal cycle. While rainfall in the peak monsoon month ranges from 7.2 to $9.1 \mathrm{~mm} / \mathrm{d}$ across observations, both CMIP3 and CMIP5 models range from $\sim 3$ to $10 \mathrm{~mm} / \mathrm{d}$. The multi-model means ( \pm 1 standard deviation) for CMIP3 and CMIP5 models are similar with a maximum of $\sim 6 \pm 2 \mathrm{~mm} / \mathrm{d}$ in August, indicating that in general the monsoon rainfall in the models is too weak. For a few models (particularly for CMIP3), there is too much rainfall outside of the monsoon season (e.g., cnrm_cm3 and inmcm3_0).

[7] Over Australia maximum observed rainfall occurs in February, ranging between 5.9 to $8.6 \mathrm{~mm} / \mathrm{d}$ across the three observational datasets (Figure $2 \mathrm{~b}$ ) with most rainfall from December to March. Again there is a considerable range in monsoon strength across the models (2 to $11 \mathrm{~mm} / \mathrm{d}$ ), although the multi-model means $(7.5 \pm 3 / 7.0 \pm 3 \mathrm{~mm} / \mathrm{d}$ for CMIP3/CMIP5) lie within the observational range. The giss_aom and ipsl_cm4 CMIP3 models have essentially no monsoon season. Most CMIP3 and CMIP5 models simulate maximum rainfall in the correct month with a few of models peaking one month early and others with an overly long rainy season (e.g., bccr_bcm2_0).

[8] In general, for both CMIP3 and CMIP5 and for both regions the range in monsoon strength across the models is about the same. However, there is a clear overall improvement in the seasonality of both monsoons from CMIP3 to CMIP5, with most CMIP5 models better simulating the monsoon timing and very low rainfall rates outside of the monsoon season.

\subsection{TBO Transitions Assessment}

[9] A Monte Carlo technique is used to assess the significance of enhanced predictability associated with the TBO. In particular we assess the success rate of the four transitions that are thought to be important for the TBO tendency starting from a given year $t$ : (1) Successful Indian-Indian out-ofphase transition is defined as $\operatorname{IMRI}(t)>0$ and $\operatorname{IMRI}(t+1)<0$ or $\operatorname{IMRI}(t)<0$ and IMRI $(t+1)>0$; (2) Successful Australian- 
(a) Seasonalily of Indian Land Precipitation CMIP3

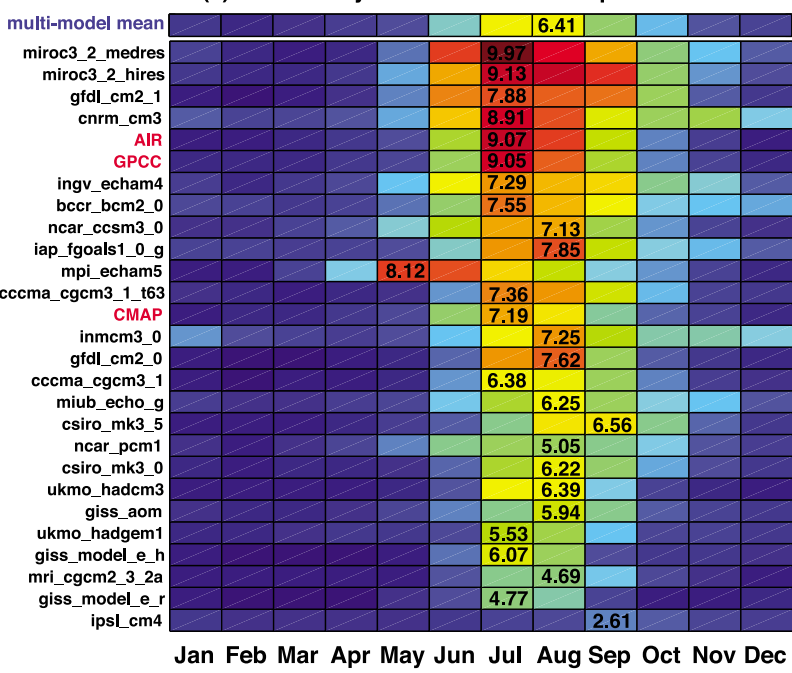

(c) Seasonality of Indian Land Precipitation CMIP5

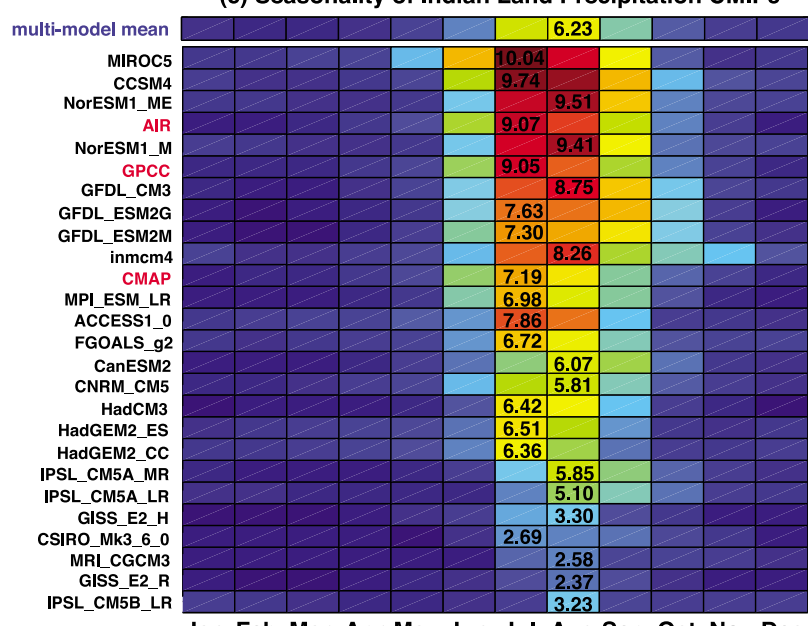

(b) Seasonalily of Australian Land Precipitation CMIP3

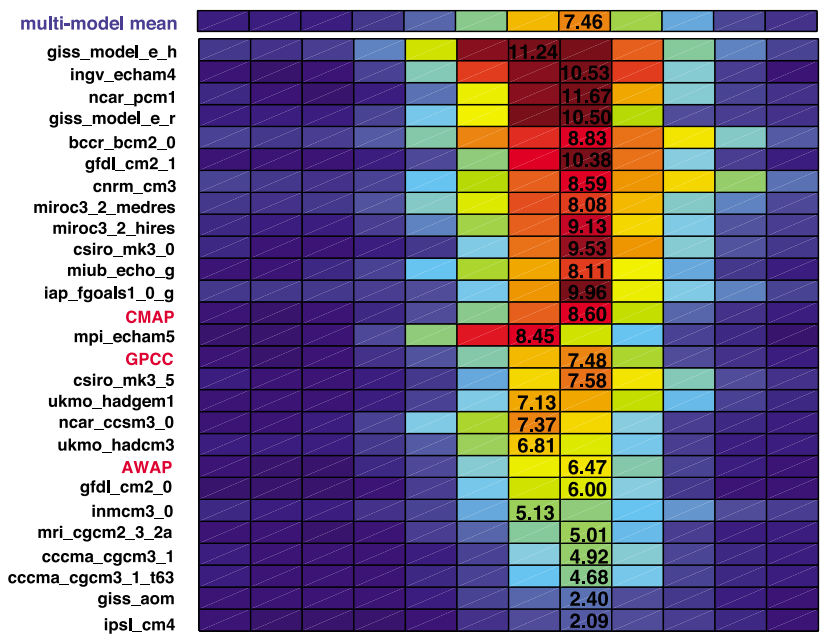

Jul Aug Sep Oct Nov Dec Jan Feb Mar Apr May Jun

(d) Seasonality of Australian Land Precipitation CMIP5

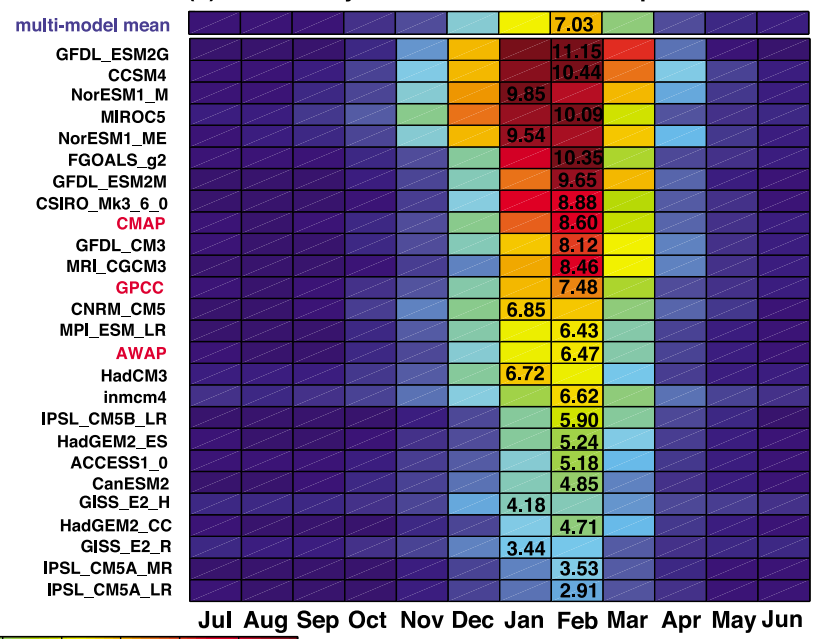

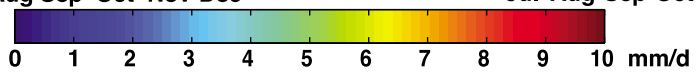

Figure 2. Seasonal cycle of the (a, c) Indian and (b, d) Australian land-restricted rainfall for observed and CMIP3 (Figures 2a and 2b) and CMIP5 (Figures 2c and 2d) models over. Models (names in black) and observations (names in red) are sorted according to the average monsoon rainfall amount (JJAS rainfall for Indian monsoon and DJFM rainfall for Australian monsoon). The top row shows the multi-model mean (names in blue) of CMIP3 or CMIP5 models for Indian and Australian rainfall. Internal numbers show the maximum rainfall $(\mathrm{mm} / \mathrm{d})$ in the month of greatest rainfall.

Australian out-of-phase transition is defined as $\operatorname{AMRI}(t)>0$ and $\operatorname{AMRI}(t+1)<0$ or $\operatorname{AMRI}(t)<0$ and $\operatorname{AMRI}(t+1)>0$; (3) Successful Indian-Australian in-phase transition is defined as $\operatorname{IMRI}(t)>0$ and $\operatorname{AMRI}(t)>0$ or $\operatorname{IMRI}(t)<0$ and $\operatorname{AMRI}(t)<0$; and, (4) Successful Australian-Indian out-of-phase transition is defined as $\operatorname{AMRI}(t)>0$ and $\operatorname{IMRI}(t+1)<0$ or $\operatorname{AMRI}(t)<0$ and $\operatorname{IMRI}(t+1)>0$.

[10] To determine the observed predictability associated with a given transition, we count the number of successful transitions in the timeseries (Figures $1 \mathrm{~b}$ and $1 \mathrm{c}$ ), relative to the total number of possible successful transitions. This is then repeated 100,000 times by randomly resampling the observed timeseries (with replacement). The predictability of the monsoon resulting from a given transition is considered enhanced if the observed or simulated percentage of successful transitions is significantly higher than the median of the randomized distribution. Moreover, the enhanced predictability is considered significant if the observed or simulated percentage of successful transitions lies in the upper decile of the randomized distributions (i.e., there is only a $10 \%$ probability of getting the enhanced predictability by chance).

[11] In the IMRI-AIR and AMRI-AWAP, only two of the four transitions show a significantly enhanced predictability over the random distribution: the Indian-Indian out-of-phase transition and the Indian-Australian in-phase transition, where the enhanced predictability from the median is $8.8 \%$ ( $\mathrm{p} \sim 0.1)$ and $\sim 15 \%(\mathrm{p} \sim 0.001)$, respectively (Figure $\mathrm{S} 1$ in the auxiliary material). ${ }^{1}$ This means that if the Indian monsoon is anomalously strong (weak) in a given year there is a $\sim 59 \%$ probability that the subsequent Indian monsoon will be anomalously weak (strong) and a $\sim 65 \%$ probability that the subsequent Australian monsoon will be anomalously strong (weak).

${ }^{1}$ Auxiliary materials are available in the HTML. doi:10.1029/ 2012GL053322. 
[12] To test the sensitivity of these results to the datasets, we compute predictability based on different datasets and time periods: CMAP (1979-2008) and GPCC (1901-2010) over the same spatial land areas (Figure 1a). Indices from both datasets show significant enhanced predictability ( $\mathrm{p} \sim$ 0.1 ) of $27.6 \%$ and $13.8 \%$, respectively, for the Indian to Australian transition. However, for the Indian-Indian out-ofphase transition, only GPCC shows an enhanced predictability of $6.4 \%(\mathrm{p} \sim 0.12)$. Given the relative shortness of the CMAP datasets, the lack of significant results might arise from multi-decadal variability of the TBO. To examine this, we divided the IMRI-AIR into a CMAP-like period (19792008) and pre-CMAP period (1871-1978). The pre-CMAP period shows significantly enhanced predictability $(10.3 \%$, $\mathrm{p} \sim 0.1)$. The predictability for over the later CMAP-like period is not significant. This suggests that the biennial tendency for the Indian-Indian out-of-phase transition has deceased in the past 30-yrs, consistent with the recent weakening of the El Niño-Indian monsoon relationship [Ummenhofer et al., 2011; Meehl and Arblaster, 2011].

[13] Figure 3 shows the enhanced predictability for the different observational datasets and selected CMIP3 and CMIP5 models for the four transitions. We only show models for which at least one ensemble member shows a significantly enhanced predictability in any of the transitions. Twelve CMIP3 and 15 CMIP5 models have at least one ensemble member with significantly enhanced predictability for the Indian-Australian in-phase transition (Figure 3a), consistent with the observations. For the CMIP5 models the range of enhanced predictability is relatively small $(5 \%-$ $15 \%$, for significant results only). As such the models generally underestimate the observed enhanced predictability of $\sim 15 \%$. For the CMIP3 models the range is larger (5-35\%). For the models with multiple ensemble members, many show contrasting results for different members, indicating a substantial multi-decadal variability in the efficacy of this transition. Nevertheless, when considering concatenated ensemble members, the Indian- Australian transition has enhanced predictability in 11 of 24 (14 of 23) CMIP3 (CMIP5) models.

[14] As noted above, the only other transition that provides significantly enhanced predictability using the long-term reference observations is the Indian-Indian out-of-phase transition, although it is mostly associated with the earlier part of the record (see discussion above). For this transition (Figure 3b), seven CMIP3 and five CMIP5 models show enhanced predictability for at least one ensemble member. In the case of models with multiple ensemble members, only a small number of members are significant (e.g., CNRM_CM5, GISS_E2_H and NorESM_M). As such, only four CMIP3 and two CMIP5 models show enhanced predictability when considering the multi-ensemble concatenation for each model.

[15] For the Australian-Indian out-of-phase transition (Figure 3c), one of the longer observational timeseries suggests a multi-decadal period when there was enhanced predictability associated with this transition. Five CMIP3 and only one CMIP5 models have ensemble members with significantly enhanced predictability, despite conflicting results within each ensemble set. Surprisingly, a large number of models actually show significant negative predictability, in particular when considering concatenated ensemble members. Negative predictability suggests that a strong (weak) Australian monsoon would tend to be followed by a strong (weak) Indian monsoon. Such behavior is not found in the observations, and might be related to bias in the simulated ENSO seasonal cycle, e.g., where La Niña events tend to persists too long this would lead to a strong Australian monsoon followed by a strong Indian monsoon (N. C. Jourdain et al., The Indo-Australian monsoon and its relationship to ENSO and IOD in reanalysis data and the CMIP3/CMIP5 simulations, submitted to Climate Dynamics, 2012). Finally for the Australian-Australian out-of-phase transition (Figure 3d), for which there is no observational evidence of enhanced predictability, eight of the CMIP3 and five of the CMIP5 models have ensemble members with significantly enhanced predictability.

[16] While the impacts of the monsoon are primarily over land, the teleconnections associated with global modes of variability can involve larger domains. To assess the effect of the monsoon in a larger context, we also derived similar rainfall indices over extended Indian and Australian regions (including the oceanic regions, Figure 1a, see methods) used in previous analysis of the TBO [e.g., Meehl and Arblaster, 2002]. Applying the Monte Carlo analysis to these indices for both CMIP3 and CMIP5 models, we find that for the Indian-Australian transition, most models show significant enhanced predictability independent of the index definition (Figure S2). For the other transitions there is little consistency with regards to predictability across the models. For the Australian-Indian transition, fewer models show the negative predictability seen with the land-only based indices. In addition for the Australian-Australian transition there are more CMIP3 models that exhibit enhanced predictability using the more inclusive index. As such, overall we do not find that the sequence of events that combine to make up the TBO is more obvious when examining a larger land-ocean area.

\section{Conclusion}

[17] This study examines the fidelity of climate models in simulating the mean state and seasonality of the Indian and Australian monsoons and the various transitions that play a role in the TBO. While almost all models produce at least some monsoon-like behavior, there are very large spreads in maximum monthly rainfall: $33 \%$ to $110 \%(50 \%$ to $170 \%)$ of the AIR/AWAP observational dataset for Indian (Australian) rainfall. The multi-model means of Indian maximum rainfall are underestimated for both CMIP3 and CMIP5 models $(6 \pm 2 \mathrm{~mm} / \mathrm{d}$ as compared to $7-9 \mathrm{~mm} / \mathrm{d}$ ), while multi-model means of Australian maximum rainfall are within the observed range $(6-9 \mathrm{~mm} / \mathrm{d})$. Most models successfully reproduce the timing of the monsoons although phase shifts of up to 2 months are evident in a few models. Overall, while there is no obvious improvement in the average summer monsoon rainfall from CMIP3 to CMIP5, in general, the CMIP5 models do show improved seasonality for both monsoons.

[18] In the observations and in the majority of the models ( 13 of 24 CMIP3 and 15 of 23 CMIP5), we find significantly enhanced predictability in the Indian-Australian in-phase transition. The observations suggest that given the strength of the Indian monsoon we have a $\sim 65 \%$ chance of correctly estimating whether the following Australian monsoon will be weaker or stronger than normal. The enhanced predictability in CMIP models is probably related to the fact that the models correctly reproduce an ENSO-monsoon link, such that an 


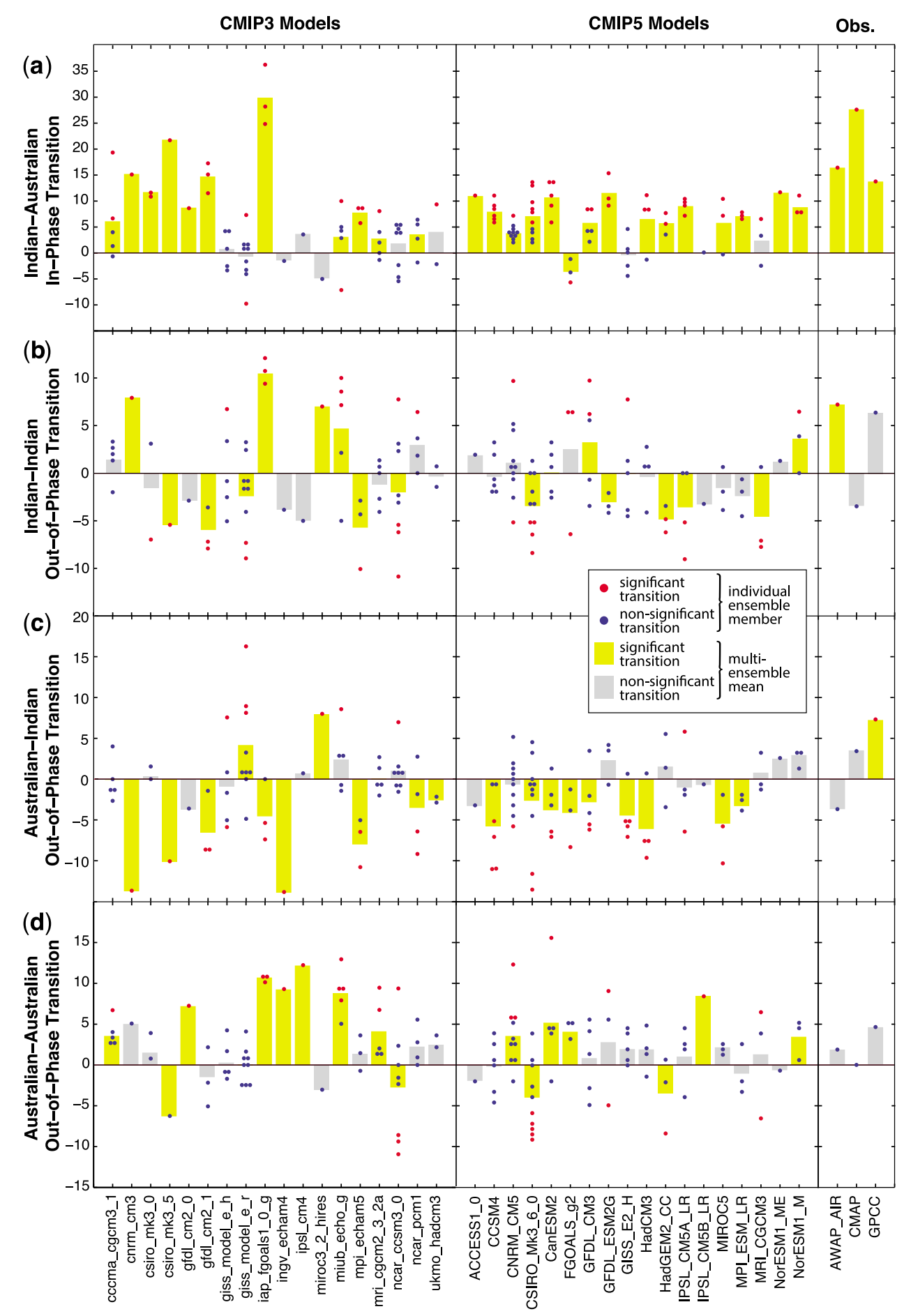

Figure 3. Percentage enhanced predictability for the (a) Indian-Australian, (b) Indian-Indian, (c) Australian-Indian and (d) Australian-Australian transitions for observations and CMIP3 and CMIP5 models for which at least one ensemble member for that model and for at least one of the transitions shows a significant increase in predictability. Circles represent individual ensemble members (marked in red are significant, $p<0.1$ ). Bars represent the multi-ensemble mean percentage enhanced predictability for each model with yellow indicating significant changes. The multi-ensemble mean predictability was calculated by concatenating time series for all ensemble members prior to Monte Carlo resampling.

El Niño (La Niña) is associated with both a weak (strong) Indian and Australian monsoon [Webster et al., 1998].

[19] The Indian-Indian out-of-phase transition is only significant in the long AIR dataset, providing enhanced predictability of $\sim 8 \%$ (Figure $3 \mathrm{~b}$ ), however it varies over certain time periods. For CMIP3 and CMIP5 models with multiple ensemble members, only some of the ensemble members show successful transitions. This suggests a highdegree of multi-decadal variability in this transition. This is consistent with previous studies looking at the observational records [e.g., Fasullo, 2004; Meehl and Arblaster, 2011]. While some models indicate significantly enhanced 
predictability, many models actually show significantly reduced predictability for the Indian-Indian and AustralianIndian out-of-phase transitions. Future work will examine the reasons behind these inter-model differences.

[20] In summary, this study examines four different TBO transitions, for which a number of different mechanisms have been proposed [e.g., Meehl and Arblaster, 2002]. Our study demonstrates that while for both observations and models the India-Australia link seems to be robust, the other transitions are both dataset and time period dependent, with a range of contrasting behaviors exhibited in the climate models. In particular there seems to be little evidence that the Australian monsoon can directly influence the subsequent Indian monsoon.

[21] Acknowledgments. We acknowledge the WCRP's Working Group on Coupled Modelling, which is responsible for CMIP, and the climate modeling groups for their model output. The U.S. DoE's PCMDI provides coordinating support for CMIP in partnership with the GOESSP. This project was supported by funding from the Australian Research Council (DP110100601) and the Centre of Excellence for Climate System Science. This work was also supported by an award under the Merit Allocation Scheme on the NCI National Facility at the ANU. Two anonymous reviewers provided helpful comments on the paper.

[22] The Editor thanks two anonymous reviewers for their assistance in evaluating this paper.

\section{References}

Chang, C.-P., and T. Li (2000), A theory for the tropical tropospheric biennial oscillation, J. Atmos. Sci., 57, 2209-2224, doi:10.1175/1520-0469(2000) 057<2209:ATFTTT>2.0.CO;2.

Fasullo, J. (2004), Biennial characteristics of all India rainfall, J. Clim., 17, 2972-2982, doi:10.1175/1520-0442(2004)017<2972:BCOIMR>2.0.CO;2.

Jones, D. A., W. Wang, and R. Fawcett (2009), High-quality spatial climate data-sets for Australia, Aust. Meteorol. Oceanogr. J., 58, 233-248.
Meehl, G. A. (1987), The annual cycle and interannual variability in the tropical Pacific and Indian Ocean regions, Mon. Weather Rev., 115, 27-50, doi:10.1175/1520-0493(1987)115<0027:TACAIV >2.0.CO;2.

Meehl, G. A. (1997), The South Asian monsoon and the tropospheric biennial oscillation, J. Clim., 10, 1921-1943, doi:10.1175/1520-0442(1997) $010<1921$ :TSAMAT $>2.0$. CO; 2 .

Meehl, G. A., and J. M. Arblaster (2002), The tropospheric biennial oscillation and Asian-Australian monsoon rainfall, J. Clim., 15, 722-744, doi:10.1175/1520-0442(2002)015<0722:TTBOAA $>2.0$. CO;2.

Meehl, G. A., and J. M. Arblaster (2011), Decadal variability of AsianAustralian monsoon-ENSO-TBO relationships, J. Clim., 24, 4925-4940, doi:10.1175/2011JCLI4015.1.

Nanjundiah, R. S., V. Vidyunmala, and J. Srinivasan (2005), The impact of increase in $\mathrm{CO}_{2}$ on the simulation of tropical biennial oscillations (TBO) in 12 coupled general circulation models, Atmos. Sci. Lett., 6(3), 183-191, doi:10.1002/asl.115.

Parthasarathy, B., A. A. Munot, and D. R. Kotawale (1995), Monthly and seasonal rainfall series for all-India homogeneous regions and meteorological sub-divisions: 1871-1994, Res. Rep. 65, Indian Inst. of Trop. Meteorol., Pune.

Rudolf, B., A. Becker, U. Schneider, A. Meyer-Christoffer, and M. Ziese (2010), GPCC Status Report, December 2010, report, 7 pp., Global Precip. Climatol. Cent., Boulder, Colo.

Ummenhofer, C. C., A. Sen Gupta, Y. Li, A. S. Taschetto, and M. H. England (2011), Multi-decadal modulation of the El Niño-Indian monsoon relationship by Indian Ocean variability, Environ. Res. Lett., 6, 034006 , doi:10.1088/1748-9326/6/3/034006.

Webster, P. J., V. O. Magaña, T. N. Palmer, J. Shukla, R. A. Tomas, M. Yanai, and T. Yasunari (1998), Monsoons: Processes, predictability, and the prospects for prediction, J. Geophys. Res., 103(C7), 14,451-14,510, doi:10.1029/97JC02719.

Wu, R. (2008), Possible role of the Indian Ocean in the in-phase transition of the Indian to Australian summer monsoon, J. Clim., 21, 5727-5741, doi:10.1175/2008JCLI2354.1.

Wu, R. (2009), Possible role of the Indian Ocean in the out-of-phase transition of the Australian to Indian summer monsoon, J. Clim., 22, 1834-1849, doi:10.1175/2008JCLI2602.1.

Xie, P., and P. A. Arkin (1996), Analyses of global monthly precipitation using gauge observations, satellite estimates, and numerical model predictions, J. Clim., 9, 840-858, doi:10.1175/1520-0442(1996)009<0840: AOGMPU $>2.0 . \mathrm{CO} ; 2$. 